\title{
BNREL
}
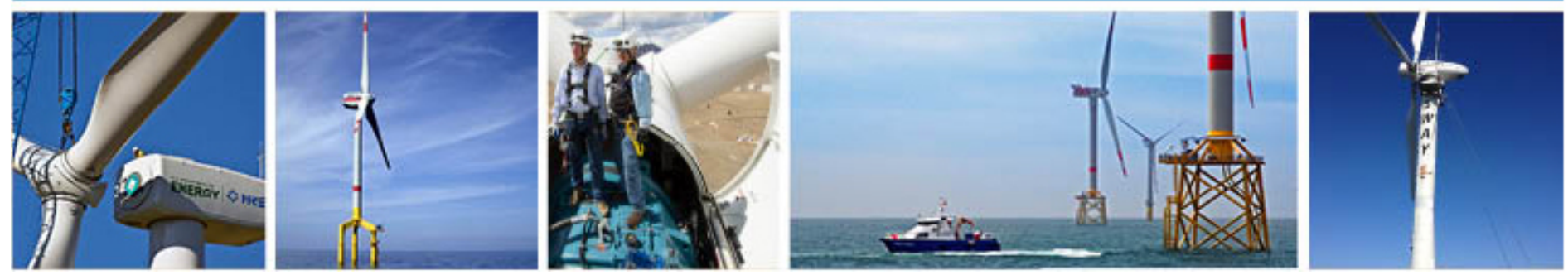

\section{Preliminary Verification and Validation of WEC-Sim, an Open-Source Wave Energy Converter Design Tool}

\section{Preprint}

K. Ruehl and C. Michelen

Sandia National Laboratories

S. Kanner

University of California Berkeley

M. Lawson and $\mathrm{Y}-\mathrm{H}$. Yu

National Renewable Energy Laboratory

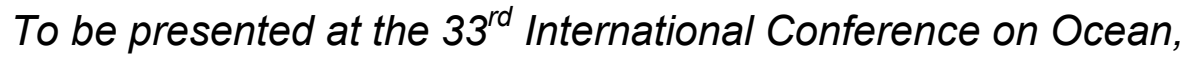
Offshore and Arctic Engineering

San Francisco, California

June 8-13, 2014

NREL is a national laboratory of the U.S. Department of Energy Office of Energy Efficiency \& Renewable Energy

Operated by the Alliance for Sustainable Energy, LLC

This report is available at no cost from the National Renewable Energy Laboratory (NREL) at www.nrel.gov/publications.

\section{Conference Paper}

NREL/CP-5000-61531

March 2014

Contract No. DE-AC36-08G028308 


\section{NOTICE}

The submitted manuscript has been offered by an employee of the Alliance for Sustainable Energy, LLC (Alliance), a contractor of the US Government under Contract No. DE-AC36-08GO28308. Accordingly, the US Government and Alliance retain a nonexclusive royalty-free license to publish or reproduce the published form of this contribution, or allow others to do so, for US Government purposes.

This report was prepared as an account of work sponsored by an agency of the United States government. Neither the United States government nor any agency thereof, nor any of their employees, makes any warranty, express or implied, or assumes any legal liability or responsibility for the accuracy, completeness, or usefulness of any information, apparatus, product, or process disclosed, or represents that its use would not infringe privately owned rights. Reference herein to any specific commercial product, process, or service by trade name, trademark, manufacturer, or otherwise does not necessarily constitute or imply its endorsement, recommendation, or favoring by the United States government or any agency thereof. The views and opinions of authors expressed herein do not necessarily state or reflect those of the United States government or any agency thereof.

This report is available at no cost from the National Renewable Energy Laboratory (NREL) at www.nrel.gov/publications.

Available electronically at http://www.osti.gov/scitech

Available for a processing fee to U.S. Department of Energy and its contractors, in paper, from:

U.S. Department of Energy

Office of Scientific and Technical Information

P.O. Box 62

Oak Ridge, TN 37831-0062

phone: 865.576 .8401

fax: 865.576 .5728

email: mailto:reports@adonis.osti.gov

Available for sale to the public, in paper, from:

U.S. Department of Commerce

National Technical Information Service

5285 Port Royal Road

Springfield, VA 22161

phone: 800.553 .6847

fax: 703.605.6900

email: orders@ntis.fedworld.gov

online ordering: http://www.ntis.gov/help/ordermethods.aspx 


\section{PRELIMINARY VERIFICATION AND VALIDATION OF WEC-SIM, AN OPEN-SOURCE WAVE ENERGY CONVERTER DESIGN TOOL}

\author{
Kelley Ruehl and Carlos Michelen \\ Sandia National Laboratories \\ Albuquerque, New Mexico USA
}

\author{
Samuel Kanner \\ University of California Berkeley \\ Berkeley, California USA
}

\author{
Michael Lawson and Yi-Hsiang Yu \\ National Renewable Energy Laboratory \\ Golden, Colorado USA
}

\begin{abstract}
To promote and support the wave energy industry, a wave energy converter (WEC) design tool, WEC-Sim, is being developed by Sandia National Laboratories and the National Renewable Energy Laboratory. In this paper, the WEC-Sim code is used to model a point absorber WEC designed by the U.S. Department of Energy's reference model project. Preliminary verification was performed by comparing results of the WEC-Sim simulation through a code-to-code comparison, utilizing the commercial codes ANSYS-AQWA, WaveDyn, and OrcaFlex. A preliminary validation of the code was also performed by comparing WEC-Sim simulation results to experimental wave tank tests.
\end{abstract}

\section{INTRODUCTION}

Even though wave energy converters (WECs) have been conceptualized and patented for over a century, most WEC developers are in technology readiness levels (TRLs) 3 through 5, corresponding to basic research and development [1-3]. Several developers have deployed scaled devices in the open ocean, and there have been a few full-scale grid connected deployments, such as the WaveGen Limpet in Islay and the Ocean Power Technologies (OPT) PowerBuoy in Hawaii. The industry, however, has yet to reach commercial viability, corresponding to TRL 9. As a result, WECs remain a nascent technology, and are highly dependent on numerical modeling and experimental testing to develop innovative designs and advanced control strategies.
For numerical modeling, wave energy developers currently depend on commercially available codes or codes developed in house to model their devices. Such software is both a financial burden on and a large time commitment for WEC developers. In addition, the codes are often limited in their ability to model the breadth of existing WEC designs. To reduce these burdens, the U.S. Department of Energy (DOE) has identified opensource code development as an area to advance WEC technology development. To meet this need, DOE has directed the National Renewable Energy Laboratory (NREL) and Sandia National Laboratories (SNL) to develop WEC-Sim, a publicly available, low-cost, open-source WEC modeling tool that is capable of running on a standard personal computer. WEC-Sim is developed in a modular structure that enables users to easily modify the code to meet their specific modeling needs. In this way, users can model a variety of WEC archetypes. WEC-Sim's code development is a multiyear effort, complete with verification and validation. This paper covers the initial results of verification and validation.

There are many different numerical approaches to model WECs, such as frequency domain boundary element method (BEM) models, time-domain equations of motion solvers, Morrison equation solvers, and spectral models. The numerical approach taken is highly dependent on the purpose of the model. To understand potential environmental impacts of WECs, spectral codes such as SWAN, TOMAWAC, and MIKE21 are used to evaluate possible impacts of wave farms on the near- and far-field wave environment [4-6]. Spectral models account for bathymetry, and are typically best at 
studying wave transformation, but are limited in their ability to model the WEC device itself. Morrison equation solvers, such as OrcaFlex, use the Morrison equation to solve floating body dynamics. These solvers are typically used to model mooring systems and as a first estimate of extreme wave loads [7]. BEM codes such as WAMIT, AQWA-FER, and OpenWARP are frequency-domain linear potential flow solvers that are beneficial to understanding a device's underlying hydrodynamics [8-10]. They are computationally efficient models that have been used to perform WEC design optimizations, and are commonly used to determine hydrodynamic coefficients for time-domain models [11-13]. Time-domain modeling codes, such as AQWA-NAUT and DRIFT, Aegir, and WaveDyn, use the Cummins impulse response function formulation to develop WEC equations of motion, and solve for the floating body dynamics $[14,9,15,16]$. The Cummins formulation was originally defined to study ship dynamics, and has been adopted to model WECs using hydrodynamic coefficients from frequency-domain codes [17]. Time-domain codes are advantageous because, although they are based on linear hydrodynamic theory, they are able to account for nonlinearities and can be used to develop WEC power performance models. Many of the existing commercial time-domain modeling codes, however, were developed for naval architecture applications, and are limited in their ability to model WECs. For example, WECs are typically multibody systems with significant hydrodynamic interactions, which are designed to move with the incident waves. They usually have complex power takeoff (PTO) systems. As a result, codes developed with the intention to model ship dynamics are not always best suited to model WECs. The singular commercial code developed specifically to model WECs is Garrad Hassan's WaveDyn. WaveDyn is a multibody time-domain simulation tool that allows users to represent a WEC by a single, fully coupled model. The code has been used to model many different WEC archetypes and has been experimentally validated [18-20]. Alternatively, WEC developers create inhouse codes to model their unique WEC design [21-23]. These codes are typically proprietary and have been internally validated. Although they may model a specific WEC device very well, they are not easily adaptable to model other WEC archetypes, because adaptability is not a priority for the developer.

In this paper, an overview of the WEC-Sim code is given, followed by its application to model a point absorber WEC, and results from WEC-Sim's preliminary verification through a code-to-code comparison and validation through an experimental comparison.

\section{WEC-SIM CODE DEVELOPMENT}

WEC-Sim is a code developed by SNL and NREL to model WECs when they are subject to operational waves. The code, which can be run on a standard personal computer, is a time-domain modeling tool developed in MATLAB/SIMULINK using the multibody dynamics solver SimMechanics [24]. WEC-Sim solves the WEC's governing equations of motion using the Cummins time-domain impulse response function formulation in 6 Degree of Freedom (DOF), as shown in Equation (1), where $F_{e}$ is the wave excitation force, the convolution integral is the wave radiation force, $F_{h s}$ is the hydrostatic restoring force, $F_{m}$ is the mooring force, $F_{P T O}$ is the PTO force, $F_{D}$ is the drag force, $m$ is the WEC mass, and $A(\infty)$ is added mass at infinite wave frequency. These hydrodynamic coefficients are currently determined by running the BEM code WAMIT as a preprocessor. Later releases of WEC-Sim will include its own BEM preprocessor, OpenWARP [10].

$$
\begin{aligned}
& F_{e}(t)-\int_{-\infty}^{t} f_{r}(t-\tau) \dot{x}(\tau) d \tau+F_{h s}(x)+F_{m}(x, \dot{x})+ \\
& F_{P T O}(\dot{x})-F_{D}(\dot{x})=(m+A(\infty)) \ddot{x}
\end{aligned}
$$

In WEC-Sim, WECs are modeled by connecting rigid bodies to one another with joint or constraint blocks from the WEC-Sim library. An example application is a two-body point absorber WEC, as shown in FIGURE 1. The "Translational PCC" (PCC stands for power conversion chains) block is a PTO model from the WEC-Sim library that simulates a PTO system operating in linear translational motion, and restricts the relative motion between the float and the spar/plate. In general, these blocks define the allowable relative motion between the WEC bodies. The WEC is connected to the world frame by a "Floating Connection (6 DOF)" joint, which allows the WEC to move freely in all 6 DOF. All other forces (such as hydrodynamics and mooring) are applied to the WEC within the WEC-Sim body blocks. The user then specifies the desired simulation parameters in an input file to run WEC-Sim.

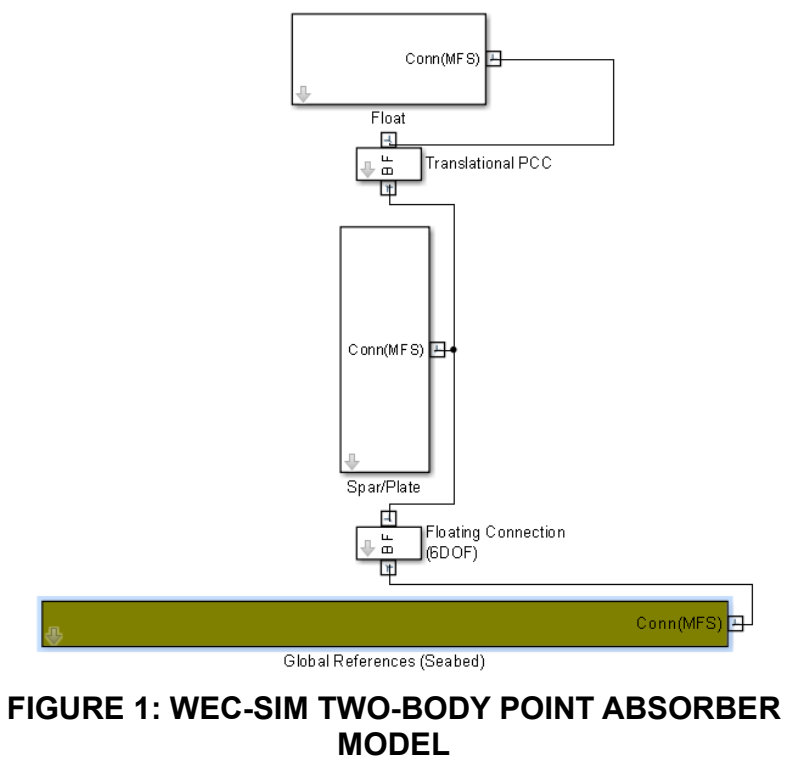

\section{REFERENCE MODEL 3 POINT ABSORBER DESIGN}

WEC-Sim was used to model the Reference Model 3 (RM3) WEC design, a heaving two-body point absorber designed through DOE's reference model project $[25,26]$. The WEC is free to move in all $6 \mathrm{DOF}$ in response to incident 
waves. Power is primarily captured in the heave direction. The RM3 device was chosen because the design has already been well characterized both numerically and experimentally as a result of a previous DOE-funded project. It also has relatively simple operating principles, and is representative of WECs currently pursued by the wave energy industry. RM3 is a heaving two-body point absorber, consisting of a float and a spar/plate, the full-scale dimensions and mass properties of which are shown in FIGURE 2 and TABLE 1. This geometry is based on the RM3 design that was tested at a 1:33 scale at Scripps Institute of Oceanography in San Diego. Accordingly, simulations of the RM3 geometry performed by WEC-Sim and commercial codes can be directly compared to experimental data.

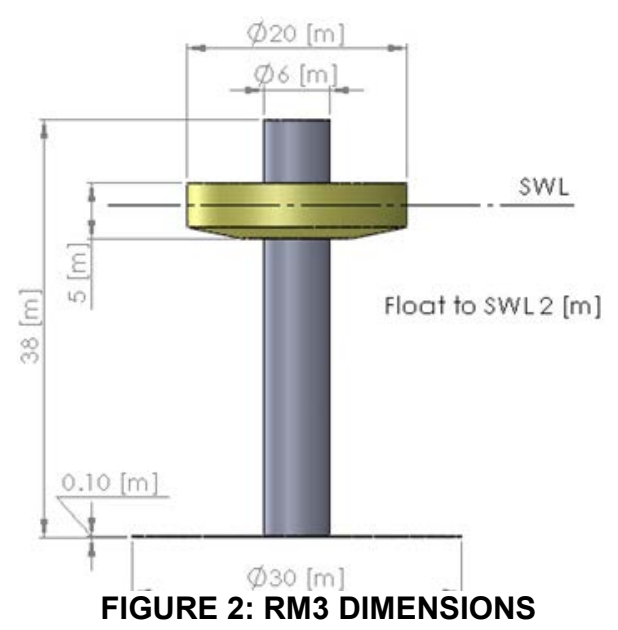

TABLE 1: RM3 MASS PROPERTIES

\begin{tabular}{|c|c|c|c|c|}
\hline \multicolumn{5}{|c|}{ Float Full Scale Properties } \\
\hline CG [m] & $\begin{array}{c}\text { Mass } \\
\text { [tonne] }\end{array}$ & \multicolumn{3}{|c|}{ Moment of Inertia $\left[\mathrm{kg}-\mathrm{m}^{2}\right]$} \\
\hline 0.00 & \multirow{3}{*}{727.01} & $2.09 E+07$ & $0.00 E+00$ & $0.00 \mathrm{E}+00$ \\
\hline 0.00 & & $0.00 \mathrm{E}+00$ & $2.13 E+07$ & $4.30 E+03$ \\
\hline-0.72 & & $0.00 \mathrm{E}+00$ & $4.30 \mathrm{E}+03$ & $3.71 \mathrm{E}+07$ \\
\hline \multicolumn{5}{|c|}{ Spar-Plate Full Scale Properties } \\
\hline CG [m] & $\begin{array}{c}\text { Mass } \\
\text { [tonne] }\end{array}$ & \multicolumn{3}{|c|}{ Moment of Inertia $\left[\mathrm{kg}-\mathrm{m}^{2}\right]$} \\
\hline 0.00 & \multirow{3}{*}{878.30} & $9.44 \mathrm{E}+07$ & $0.00 E+00$ & $0.00 E+00$ \\
\hline 0.00 & & $0.00 E+00$ & $9.44 \mathrm{E}+07$ & $2.18 \mathrm{E}+05$ \\
\hline-21.29 & & $0.00 E+00$ & $2.18 \mathrm{E}+05$ & $2.85 \mathrm{E}+07$ \\
\hline
\end{tabular}

\section{VERIFICATION}

To verify the functionality of WEC-Sim, a code-to-code comparison was performed, in which the RM3 point absorber design was simulated in WEC-Sim, and compared to simulation of the same device using the commercial codes WaveDyn, AQWA, and OrcaFlex. The RM3 point absorber was first modeled with 1 DOF (heave only) in WEC-Sim, WaveDyn, and AQWA. Next, the RM3 point absorber was modeled with 3 DOF (heave, pitch, and surge) in WEC-Sim and OrcaFlex. In the following subsections, results from the code-to-code comparison for both the $1 \mathrm{DOF}$ and 3 DOF simulations are presented.

\section{Heave (1 DOF) Simulation}

The first verification effort for WEC-Sim was performed by modeling the RM3 point absorber in 1 DOF using WECSim, and comparing its results to the commercial codes WaveDyn and AQWA. All three codes were run for regular waves with period $\mathrm{T}=8 \mathrm{~s}$ and wave height of $\mathrm{H}=2.5 \mathrm{~m}$, where the WEC motion was restricted to heave only, and did not include any motion resulting from coupled DOFs. Simulations were run without PTO damping and with PTO damping of $1,200 \mathrm{kN}-\mathrm{s} / \mathrm{m}$ between the float and spar/plate.

\section{Simulations without Power Take-off}

Simulation results from RM3 regular wave runs without PTO damping have very good agreement in terms of both the amplitude and phase among all three codes. The entire WECSim simulation float response is shown in FIGURE 3, and the last few wave periods of the float and spar/plate responses are shown in FIGURE 4. The full time-series figures show the overall trends in the WEC heave response, and show the different ramping functions for each of the models. WaveDyn uses a simple linear ramping function, whereas WEC-Sim uses a $\cos ^{2}$ function and AQWA uses a $\sin ^{2}$ function. The WaveDyn and WEC-Sim simulations use hydrodynamic coefficients from the same WAMIT run, whereas the AQWA simulation uses hydrodynamic coefficients from its own BEM solver. The WAMIT and AQWA hydrodynamic coefficients were verified before running the time-domain simulations. As a result, the simulations should agree almost perfectly because they are solving the same governing equations. Both the float and spar/plate responses from the regular wave simulation have very good agreement between WEC-Sim, WaveDyn, and AQWA, as shown in FIGURE 4, in which the float response is shown as a solid line, and the spar/plate is indicated with a dotted line. There is a minimal difference of approximately 0.02 $\mathrm{m}$ between the WEC-Sim results and those from AQWA and WaveDyn. Because the WEC's power performance is a function of the relative motion between the float and the spar/plate, this is an important metric for gauging overall code performance. As shown in FIGURE 5, the relative heave motion shows very good agreement in terms of both the amplitude and phase for all three codes, with the AQWA and WEC-Sim responses within $0.01 \mathrm{~m}$, and WaveDyn within $0.04 \mathrm{~m}$. 


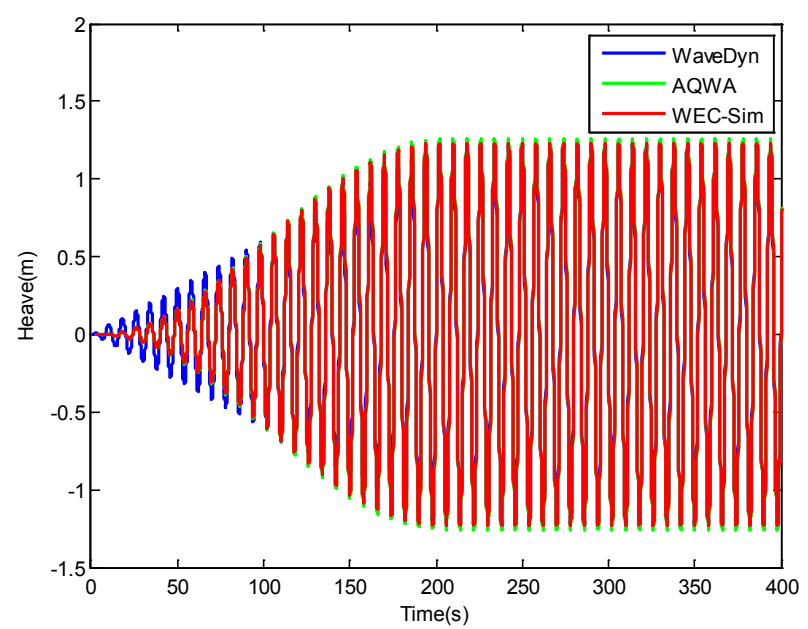

FIGURE 3: 1 DOF HEAVE FLOAT RESPONSE WITHOUT PTO, FOR THE FULL TIME SERIES

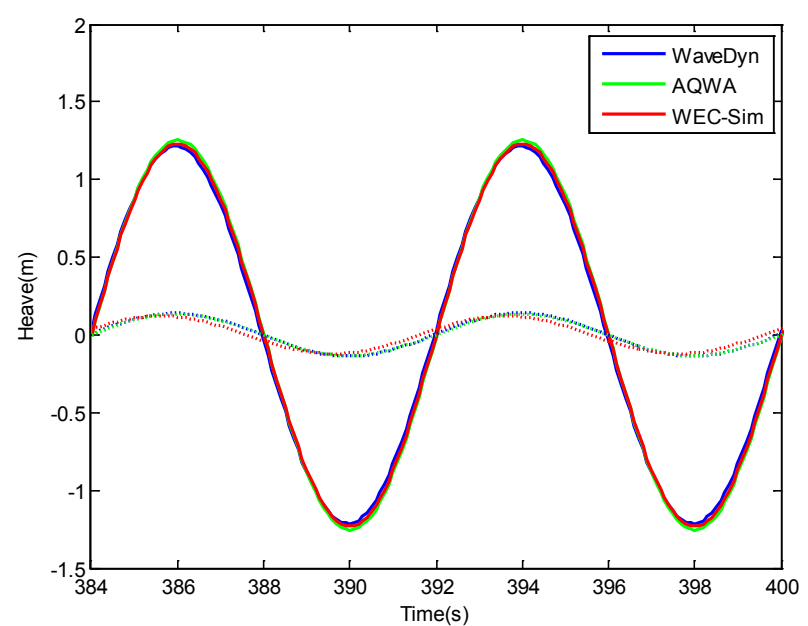

FIGURE 4: 1 DOF HEAVE FLOAT (SOLID) AND SPAR/PLATE (DASHED) RESPONSE WITHOUT PTO, FOR THE LAST WAVE PERIODS

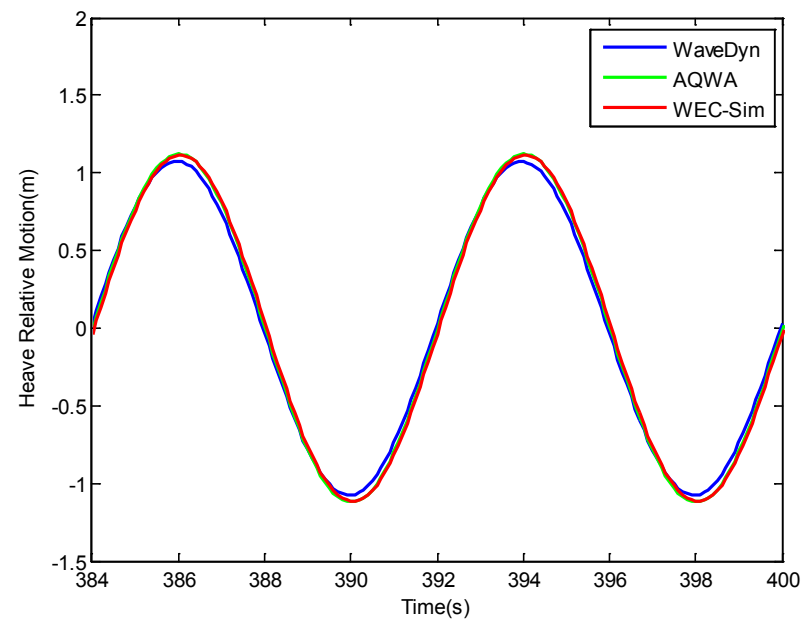

FIGURE 5: 1 DOF HEAVE RELATIVE MOTION BETWEEN THE FLOAT AND SPAR/PLATE WITHOUT PTO, FOR THE LAST WAVE PERIODS

\section{Simulations with Power Take-off}

Simulation results from RM3 regular wave simulations with PTO damping of 1,200 kN-s/m have very good agreement between all three codes. The float and spar/plate response for the runs with PTO damping agree well in terms of both the response amplitude and phase. As shown in FIGURE 6, the WEC-Sim and WaveDyn results have especially good phase and amplitude agreement for the relative motion, with a maximum difference of less than $0.03 \mathrm{~m}$. AQWA's simulated relative response, however, is slightly shifted. This disagreement stems from how AQWA models the PTO damping, because it does not allow for damping between bodies in relative translational motion. Instead, an external damping value must be applied to each individual body. As a result, there is a lag in AQWA's response compared to WECSim and WaveDyn, which easily allow for damping in relative translational motion.

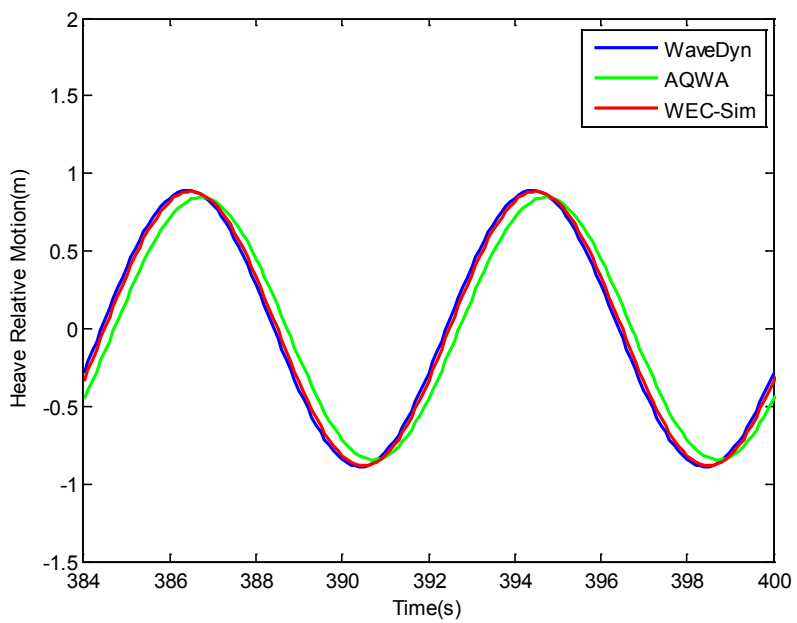

FIGURE 6: 1 DOF HEAVE RELATIVE MOTION BETWEEN THE FLOAT AND SPAR/PLATE WITH PTO DAMPING, FOR THE LAST WAVE PERIODS

\section{Heave, Pitch, and Surge (3 DOF) Simulation}

To further verify WEC-Sim, the WEC-Sim team also performed simulations in 3 DOF without PTO damping, where the device was allowed to move freely in heave, surge, and pitch. The simulation results from WEC-Sim were compared to results from OrcaFlex. In the OrcaFlex simulation, the float and the spar/plate were modeled as two separate vessels connected with a spring-damper link, which contained infinite bending stiffness so that the float was restricted to motion along the spar. Because OrcaFlex only accepts single-body WAMIT hydrodynamic coefficients for each body, the WEC-Sim code was modified so that the two codes used exactly the same WAMIT hydrodynamic coefficients to simulate the problem in the same way.

The analysis was conducted with regular waves, for wave height, $\mathrm{H}=2.5 \mathrm{~m}$, and for wave periods, $\mathrm{T}=8 \mathrm{~s}$ and $12 \mathrm{~s}$, without PTO damping. Only the 12 s runs are shown in this paper. The time history of the device pitch response and the 
relative motion between the float and the spar/plate obtained from WEC-Sim and OrcaFlex were compared, and the results are plotted in FIGURE 7 and FIGURE 8. A half cosine ramp function, which was similar to the one used in OrcaFlex, was applied in WEC-Sim to slowly start the simulations to minimize the transient response. Results from WEC-Sim 3 DOF simulation agreed very well with those obtained from OrcaFlex. The heave response agrees very well in terms of both amplitude and phase, with a maximum difference of around $0.01 \mathrm{~m}$. Similarly, the pitch response agreed very well, with a maximum difference between OrcaFlex and WEC-Sim of 0.03 deg.

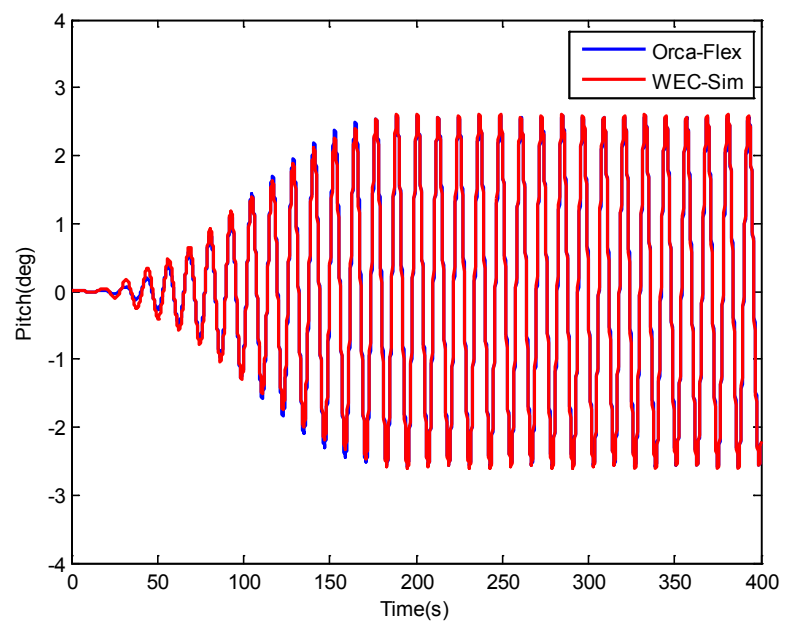

FIGURE 7: 3 DOF PITCH RESPONSE FOR THE RM3, FOR THE FULL TIME SERIES

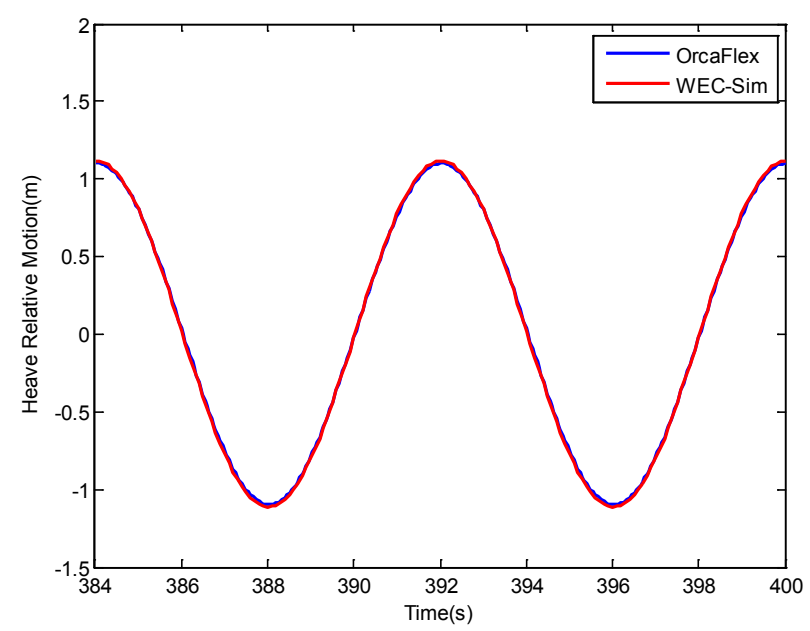

FIGURE 8: 3 DOF HEAVE RELATIVE MOTION BETWEEN THE FLOAT AND SPAR/PLATE WITHOUT PTO DAMPING, FOR THE LAST WAVE PERIODS

\section{EXPERIMENTAL VALIDATION}

Preliminary validation of WEC-Sim was also performed, by comparing the results of the WEC-Sim simulation of the RM3 two-body point absorber WEC to experimental wave tank data from a 1:33 Froude scale device tested at the Scripps
Institute of Oceanography in San Diego in December 2011. The RM3 experimental tests were performed as part of DOE's reference model project. Further WEC-Sim validation is planned through a series of dedicated wave tank experiments, after the code has its initial public release. The results given in the following sections are not from this dedicated WEC-Sim validation effort, and instead leverage existing data sets for preliminary WEC-Sim validation.

For the WEC-Sim simulations, the RM3 WEC tested at Scripps has been scaled to full scale, using the dimensions and mass properties shown in FIGURE 2 and TABLE 1 (full-scale water depth, $\mathrm{h}=49.5 \mathrm{~m}$, and water density, $\rho=1,000 \mathrm{~kg} / \mathrm{m}^{3}$ ). PTO damping was applied between the float and spar/plate in the experiments. Details on these experiments will be posted to the reference model website in September 2014 [27].

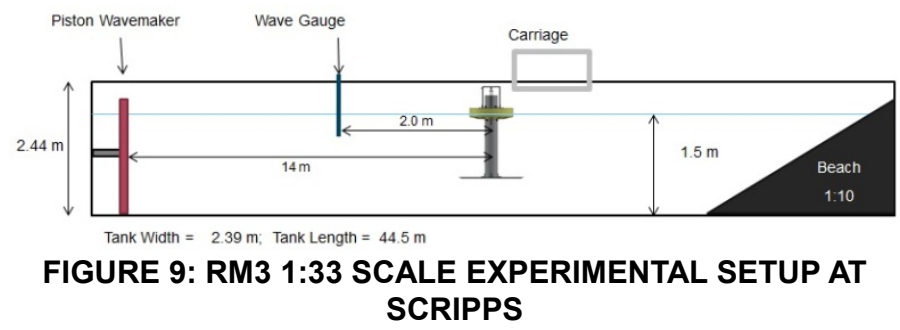

The simulations of the RM3 WEC were performed at full scale for wave height, $\mathrm{H}=3 \mathrm{~m}$, and for wave periods ranging from 8 to $18 \mathrm{~s}$, with a time-step of $0.01 \mathrm{~s}$. For the WEC-Sim simulations, the PTO damping was assumed to be linear, and set to the average full-scale experimental damping value, 2,500 $\mathrm{kN}-\mathrm{s} / \mathrm{m}$. Viscous drag plays a significant role in WEC motion, and tuning its numerical value is critical, especially for comparison to small-scale experimental data. In these simulations, the WEC-Sim code was run with the float drag coefficient set to 1.4 , and the damping plate set to 4.3. Because the RM3's PTO is dependent on the relative motion between the float and the spar/plate, the relative heave motion response amplitude operators (RAOs) were used as a validation metric. The experimental RAOs are shown in FIGURE 10 as blue diamonds, and the WEC-Sim results are shown as a red dotted line. The WEC-Sim simulation accurately reproduces the RAO shape and magnitude, and does not systematically over- or underpredict device response. This serves as preliminary code validation by demonstrating WEC-Sim's ability to reproduce experimental results. Without experimental data or computational fluid dynamic simulations to estimate the viscous forces, however, WEC-Sim's predictions can be highly inaccurate (much like any other linear hydrodynamic software). 


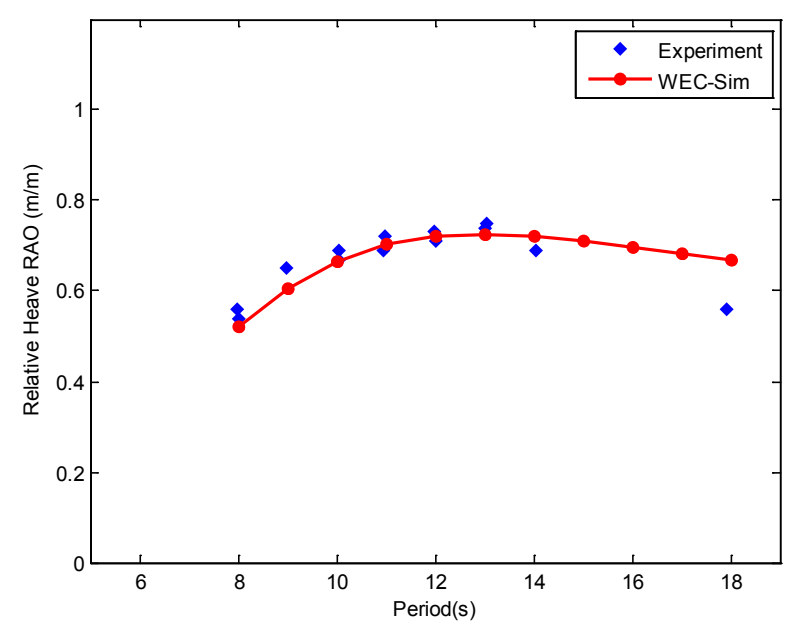

FIGURE 10: WEC-SIM SIMULATION COMPARISON TO RM3 EXPERIMENTS

\section{CONCLUSIONS AND FUTURE WORK}

SNL and NREL have developed WEC-Sim, a publicly available, low-cost, open-source, time-domain WEC modeling code that is capable of running on a standard personal computer. The code is currently developed in MATLAB/SIMLUNK, using the multibody dynamics solver SimMechanics. SNL and NREL plan to publicly release the code in summer 2014, complete with a WEC-Sim library, example applications of the code, and a user's manual. After its initial public release, the WEC-Sim team will begin conducting dedicated WEC-Sim experimental validation testing. Data from these tests will be publicly released in the second release of the code.

The work presented in this paper describes the application of the WEC-Sim code to model the RM3 WEC, a point absorber WEC designed as part DOE's reference model project. The WEC-Sim code was then verified by code-to-code comparison to the commercial codes ANSYS-AQWA, WaveDyn, and OrcaFlex. One and three DOF simulations were run for a series of operational wave cases, both with and without PTO damping. Results from these verification runs are presented in this paper, along with preliminary experimental validation by comparison to the wave tank test. Ongoing WECSim development work includes application of the WEC-Sim code to model an oscillating wave surge device, and development of nonlinear hydrodynamics $[28,29]$. SNL is also developing PTO-Sim, the WEC-Sim module to simulate WEC PCCs, which will allow users to pull component blocks from the PTO-Sim library to model their specific PTO system.

\section{ACKNOWLEDGMENTS}

This research was made possible by support from the Wind and Water Power Technologies Office within the DOE Office of Energy Efficiency \& Renewable Energy. The work was supported by Sandia National Laboratories and by the National Renewable Energy Laboratory. Sandia National Laboratories is a multi-program laboratory managed and operated by Sandia
Corporation, a wholly owned subsidiary of Lockheed Martin Corporation, for the U.S. Department of Energy's National Nuclear Security Administration under contract DE-AC0494AL85000. Special thanks to Chad Hotimsky and Adam Nelessen for their support on the development of WEC-Sim and data analysis.

\section{REFERENCES}

[1] McCormick, M. E., 1981, Ocean Wave Energy Conversion, Wiley, USA.

[2] Reed, M., Bagbey, R., Moreno, A., Ramsey, T., and Rieks, J., 2010, "Accelerating the U.S. Marine and Hydrokinetic Technology Development through the Application of Technology Readiness Levels (TRLs)," Energy Ocean 2010, Washington, DC.

[3] Ruehl, K., and Bull, D., 2012, "Wave Energy Development Roadmap: Design to Commercialization," Oceans 2012, Virginia Beach, VA.

[4] “TU Delft: SWAN." [Online]. http://www.swan.tudelft.nl/.

[5] "TOMAWAC" [Online] http://www.opentelemac.org/index.php/presentation?id=20

[6] "MIKE 21." [Online] http://www.mikebydhi.com/Products/CoastAndSea/MIKE 21.aspx.

[7] "Orcina: OrcaFlex." [Online] http://www.orcina.com/SoftwareProducts/OrcaFlex/.

[8] "Wamit, Inc. - The State of the Art in Wave Interaction Analysis." [Online] http://www.wamit.com/.

[9] “ANSYS AQWA." [Online] http://www.ansys.com/Products/Other+Products/ANSYS+ AQWA.

[10] "Open-WARP | DOE." [Online] http://www.topcoder.com/doe/challenge-details/

[11] Folley, M., Wittaker, T. W. T., and van't Hoff, J., 2007, "The Design of Small Seabed-Mounted Bottom-Hinged Wave Energy Converters," Proceedings of the 7th European Wave and Tidal Energy Conference, Porto, Portugal.

[12] Cameron, L., Doherty, R., Henry, A., Doherty, K., Hoff, J. V., Kaye, D., Naylor, D., Bourdier, S., and Whittaker, T., 2010, "Design of the Next Generation of the Oyster Wave Energy Converter," 3rd International Conference on Ocean Energy, Bilbao, Spain.

[13] Alves, M., Traylor, H., and Sarmento, A., 2007, "Hydrodynamic Optimization of a Wave Energy Converter Using a Heave Motion Buoy," Proceedings of the 7th European Wave and Tidal Energy Conference, Porto, Portugal.

[14] Cummins, WE, 1962, “The Impulse Response Function and Ship Motions," Schiffstechnik, vol. 47, no. 9, pp. 101109.

[15] "WaveDyn - DNV GL - RENEWABLES ADVISORY SOFTWARE.” [Online] http://www.glgarradhassan.com/en/software/25900.php. 
[16] Kring, D., and Sclavounos, P., 1995, "Numerical Stability Analysis for Time-Domain Ship Motion Simulations," J. Ship Res., 39(4), pp. 313-320.

[17] Falnes, J., 2002, Ocean Waves and Oscillating Systems: Linear Interactions including Wave-Energy Extraction. Cambridge University Press, Cambridge, UK.

[18] Lucas, J., Livingstone, M., Vuorinen, M., and Cruz, J., 2012, "Development of a Wave Energy Converter (WEC) Design Tool - Application to the WaveRoller WEC including Validation of Numerical Estimates," ICOE 2012, Dublin, Ireland.

[19] Mackay, E. B. L., Cruz, J., Livingstone, M., and Arnold, P., 2013, "Validation of a Time-Domain Modelling Tool for Wave Energy Converter Arrays," EWTEC 2013, Aalborg, Denmark.

[20] Cruz, J., Mackay, E., Livingstone, M., and Child, B., 2013, "Validation of Design and Plannng Tools for Wave Energy Converters (WECs)," METS 2013, Washington, DC.

[21] Caljouw, R., Harrowfield, D., Mann, L., and Fievez, J., 2011, "Testing and Model Evaluation of a Scale CETO Unit. Towards the Deployment of a Commercial Scale CETO Wave Energy Converter," Proceedings of the 9th European Wave and Tidal Energy Conference (EWTEC), Southampton, UK.

[22] Retzler, C. H., and Pizer, D. J., 2001, “The Hydrodynamics of the PELAMIS Wave Energy Device:
Experimental and Numerical Results," Proceedings of the 20th International Conference on Offshore Mechanics and Arctic Engineering (OMAE), Rio de Janeiro, Brazil.

[23] Le-Ngoc, L., Gardiner, A. I., Stuart, R. J., Caughley, A. J., and Huckerby, J. A., 2010, "Progress in the Development of a Multi-Mode Self-Reacting Wave Energy Converter," OCEANS 2010 IEEE, Sydney, pp. 1-7.

[24] "MATLAB - The Language of Technical Computing." [Online] http://www.mathworks.com/products/matlab/.

[25] Li, Y., Yu, Y.-H., Previsic, M., Nelson, E., and Thresher, R., 2011, "Numerical and Experimental Investigation of a Floating Point Absorber Wave Energy Converter under Extreme Wave Condition," IWWFB 2011, Athens, Greece.

[26] Yu, Y.-H. and Li, Y., 2013, "Reynolds-Averaged NavierStokes Simulation of the Heave Performance of a TwoBody Floating-Point Absorber Wave Energy System," Comput. Fluids, 73, pp. 104-114.

[27] "Sandia National Laboratories: Reference Model Documents." [Online] http://energy.sandia.gov/?page_id=16798.

[28] Yu Y., et al., 2014, "Design and Analysis of a TensionMoored Pitching-Type Wave Energy Converter," to be published in Proceedings of OMAE 2014.

[29] Lawson, M.J., et al., 2014, "Effects of Non-Linear Buoyancy on Simulations of Wave Energy Converters," to be published in Proceedings of OMAE 2014. 